\title{
Interaction of Cysteine and Nitrilotriacetate with Transition Metal Ions: A Solution Ionophoretic Technique Investigation
}

\author{
PRAVEEN P. SINGH* and SUDHANSHU KANAUJIA
}

Department of Chemistry, United College of Engineering \& Research, Naini, Allahabad, U.P.-211010, India

ppsingh23@gmail.com

Received 21 October 2012 / Accepted 15 November 2012

\begin{abstract}
In the work ionophoretic technique has been used for the study of $\mathrm{Fe}(\mathrm{III}), \mathrm{Cu}(\mathrm{II}), \mathrm{Ni}(\mathrm{II})$ and $\mathrm{Co}(\mathrm{II})$-cysteine binary and $\mathrm{Fe}(\mathrm{III}), \mathrm{Cu}$ (II), Ni(II) and $\mathrm{Co}(\mathrm{II})$-cysteine-NTA (Nitrilotriacetic acid) mixed complexes. The stability constants of metal-cysteine binary complexes are found to be $10^{11.30}, 10^{10.00}$, $10^{9.10}, 10^{8.90}$ and the stability constants of metal-cysteine-NTA mixed complexes have been found to be $10^{8.40}, 10^{6.80}, 10^{6.00} 10^{5.50}$ for $\mathrm{Fe}(\mathrm{III}), \mathrm{Cu}(\mathrm{II}), \mathrm{Ni}(\mathrm{II})$ and $\mathrm{Co}(\mathrm{II})$ complexes respectively at $\mu=0.1 \mathrm{M}$ $\left(\mathrm{HClO}_{4}\right)$ and $25^{\circ} \mathrm{C}$.
\end{abstract}

Keywords: Binary complex, Ternary complex, Stability constant, Ionophoretic technique

\section{Introduction}

The biological importance of metal-cysteine interactions has been relevant factor in the development of the coordination chemistry of cysteine molecules ${ }^{1,2}$. The significance of sulphur containing amino acids like cysteine is enhanced by the fact that in recent years, it has been utilized in connection with Alzheimer's disease ${ }^{3-6}$. Mixed metal complexes play an important role in various biological systems ${ }^{7}$ and in different field of chemistry ${ }^{8}$. Their biological importance is attributed to the capabilities of the mercapto groups to undergo various complex formation processes. $\mathrm{Fe}(\mathrm{III}), \mathrm{Cu}$ (II), $\mathrm{Ni}(\mathrm{II})$ and $\mathrm{Co}$ (II) are well known for their biomedical applications and play essential role in different physiological processes of the body ${ }^{9-24}$. Many transition metal amino acid complexes have considerable biological activity, such as antitumor properties. Amino acid usually increases the diffusibility of complex and enhances their biological action inside the cell. Such systems are widely used in the chemotherapy ${ }^{25}$. A number of metal-cysteine complexes have been found to show antimicrobial activity ${ }^{26}$. Because of the importance of cysteine and these metal ions, they have been chosen for the present study. 


\section{Experimental}

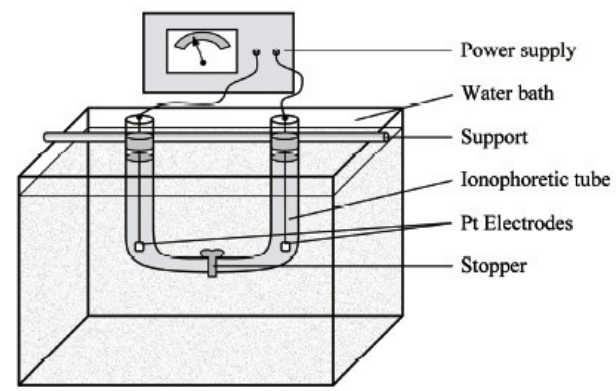

Figure 1. Experimental setup

\section{Instruments}

Electrophoresis equipment from systronic (Naroda, India) model 604 was used. It has a built in power supply (AC-DC) that is fed directly to an electrophoretic tube $(18 \mathrm{~cm}$ long and $0.5 \mathrm{~cm}$ bore) with a stopper in the middle was fused perpendicularly at the ends with short wider tubes of $1.2 \mathrm{~cm}$ bore. This tube is kept in a thermostatic water bath at $25{ }^{\circ} \mathrm{C}$ (Figure 1). $\mathrm{pH}$ measurements were made with century $\mathrm{CP} 901$ digital $\mathrm{pH}$ meter using a glass electrode. The absorbance were measured with SPECTROCHEM MK II (PEI) spectrocolorimeter. A SICO made constant temperature water bath has been used to ensure uniform temperature.

\section{Chemicals}

$\mathrm{Fe}(\mathrm{III}), \mathrm{Cu}$ (II), $\mathrm{Ni}$ (II) and $\mathrm{Co}$ (II) perchlorate solutions were prepared by precipitating the corresponding carbonates from solution of chlorides (A.R. grade) with the solution of sodium carbonate, washing the precipitates thoroughly with boiling water and dissolving in a suitable amount of perchloric acid. The resulting solutions were heated to boiling on a water bath and then filtered. The solutions were standardized and diluted with distilled water as required. AR grade cysteine, $\mathrm{NaOH}, \mathrm{HClO}_{4}$ and developing reagent for colour development were used for specific colour development for different metal ions of binary system sets.

\section{Electrolytic solutions}

For binary systems $15 \mathrm{~mL}$ solution each containing $1 \times 10^{-3} \mathrm{M} \mathrm{Cu}(\mathrm{II}) / \mathrm{Ni}(\mathrm{II}) / \mathrm{Co}(\mathrm{II}), 0.1 \mathrm{M}$ $\mathrm{HClO}_{4}$ and $1 \times 10^{-2} \mathrm{M}$ cysteine was prepared at different $\mathrm{pH}$ values (by adding $\mathrm{NaOH}$ solution). In case of $\mathrm{Fe}(\mathrm{III}), 1 \times 10^{-4} \mathrm{M} \mathrm{Fe}(\mathrm{III}), 0.1 \mathrm{M} \mathrm{HClO}_{4}$ and $1 \times 10^{-3} \mathrm{M}$ cysteine was used. For ternary systems the study was carried out by preparing sets of $15 \mathrm{~mL}$ solutions by progressive addition of secondary ligand NTA from $1 \times 10^{-6} \mathrm{M}$ to $1 \times 10^{-2} \mathrm{M}$ at a fixed $\mathrm{pH} 8.5$ to a mixture of metal ion (having same concentration as in binary systems), $1 \times 10^{-2} \mathrm{M}$ cysteine and $0.1 \mathrm{M}$ perchloric acid.

\section{Procedure}

\section{Metal-cysteine binary system}

$10 \mathrm{~mL}$ of electrolytic solution as mentioned for binary system was taken in an ionophoretic tube and then thermostated at $25{ }^{\circ} \mathrm{C}$. The position of the tube was adjusted in such a way that the level of the solution in one wide end arm reached a circular mark on it. This adjustment fixed the volume of the solution in both sides of the middle stopper. Two $(0.5 \mathrm{~cm} \times 0.5 \mathrm{~cm})$ platinum electrodes were dipped in each arm cup and a $50 \mathrm{~V}$ potential difference was applied between them. Electrolysis of the solution was allowed for 45 minutes, 
after which the middle stopper of the tube is closed. The solution of the anodic compartment was taken out in a $15 \mathrm{~mL}$ flask. The copper content of the solution was converted into copper thiocyanate ${ }^{27}$. The volume was raised to a mark in the flask and the absorbance at $408 \mathrm{~nm}$ was measured with spectrocolorimeter. The Co(II) content of the anodic compartment was converted into cobalt thiocyanate ${ }^{27}$ complex and absorbance at $625 \mathrm{~nm}$ was measured after making up the volume to $15 \mathrm{~mL}$. The Ni(II) content was converted to nickel dimethylglyoximate ${ }^{28}$ and absorbance was taken at 445 nm. Similarly the Fe(III) content of the anodic compartment was converted to $\mathrm{Fe}$ thiocyanate ${ }^{28}$ complex and absorbance was measured at $480 \mathrm{~nm}$ against a reagent blank. The same experiment is performed at different $\mathrm{pH}$ and the observations are graphically represented in Figure 2.

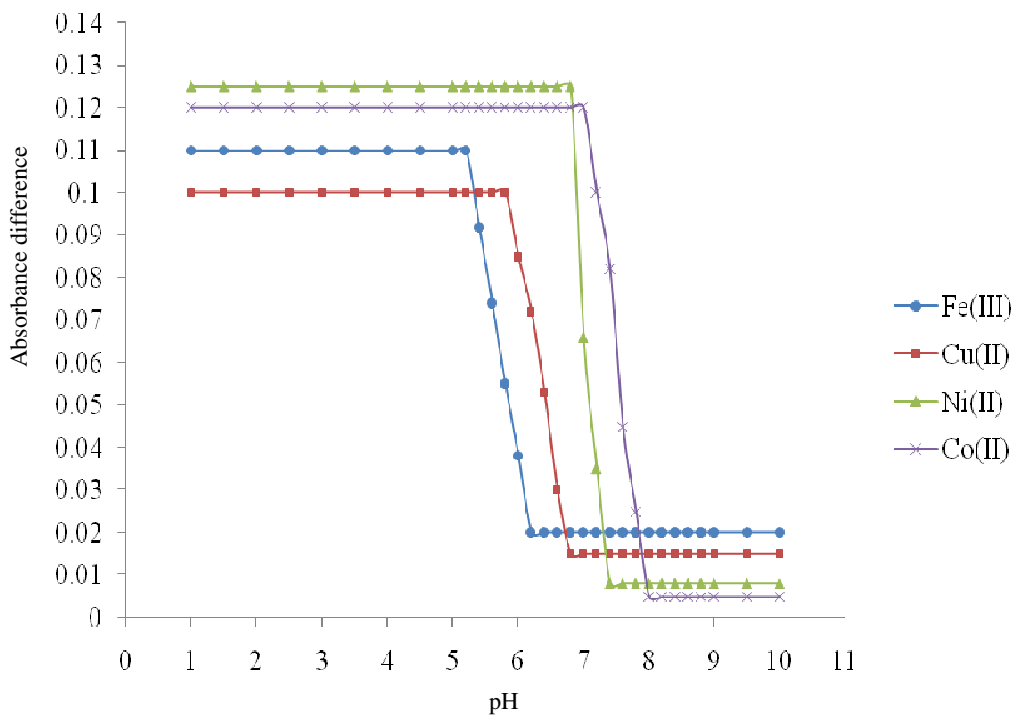

Figure 2. Mobility curve of metal-cysteine complex

\section{Metal-nitrilotriacetate binary system}

The experiments for binary complexes of the $\mathrm{Fe}(\mathrm{III}), \mathrm{Cu}(\mathrm{II}), \mathrm{Ni}(\mathrm{II})$ and $\mathrm{Co}(\mathrm{II})-\mathrm{NTA}$ are prerequisite for the study of metal-cysteine-NTA ternary complexes. These studies have been carried out by S. Aziz ${ }^{29}$ and Praveen P. Singh ${ }^{30-32}$. Their observations have been taken for comparison with our observations found in case of ternary complexes.

\section{Metal-cysteine-nitrilotriacetate ternary system}

The study of mixed complexes was carried out by progressive addition of secondary ligand NTA from $1 \times 10^{-6} \mathrm{M}$ to $1 \times 10^{-2} \mathrm{M}$ at a fixed $\mathrm{pH} 8.5$ to a mixture of metal ion (having same concentration as in binary systems), $1 \times 10^{-2} \mathrm{M}$ cysteine and $0.1 \mathrm{M}$ perchloric acid. The reason behind keeping the reaction mixture at $\mathrm{pH} 8.5$ is that much ahead of this $\mathrm{pH}$ the simple binary complexes of metal cysteine and M-NTA are formed and remain intact even beyond this $\mathrm{pH}$. The amount of secondary ligand NTA was increased each time in the ionophoretic tube and the electrolysis of the solution was allowed and its observations were recorded each time as it was done in case of binary complexes. These observations are graphically represented in Figure 3. 


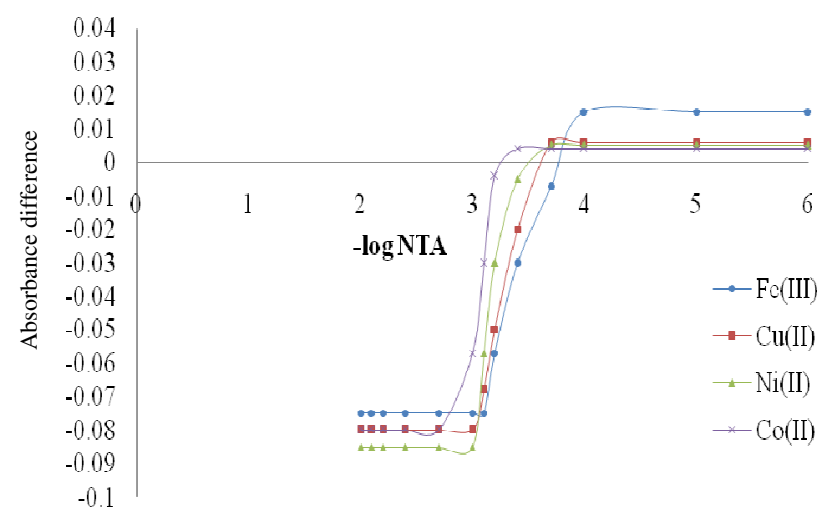

Figure 3. Mobility curve of metal-cysteine- NTA Complex

A number of factors ${ }^{33}$ (e.g. diffusion, ionic strength and temperature) obviously vitiate the ionophoretic mobility of a particular ion. The technique described here is almost free of these vitiating factors and the reliability may vary to $\pm 2 \%$.

As for the possibility of hydroxy compound formation, we had considered this aspect in our earlier studies. For this we performed the study of binary complex formation at two different concentrations of ligand giving complexing species at two different $\mathrm{pH}$ values. In that study we found two different plateaus but almost same stability constant. If it would have been a hydroxyl complex only one plateau at fixed $\mathrm{pH}$ value must have been formed irrespective of different concentration of ligand (cysteine here) used. This clearly indicates that at very low concentration of metal (i.e. Fe(III) $\left.=10^{-4} \mathrm{M}\right)$ no hydroxy compound are formed. Hence the possibility of hydroxy compound formation at very low concentrations of metal ions is ignored in these studies.

\section{Results and Discussion}

\section{Metal-cysteine binary system}

Figure 2 illustrates the relationship between absorbance differences and the $\mathrm{pH}$ and thus gives an idea of the change of overall mobility of the metal ion species with change in hydrogen ion status of the system containing $\mathrm{Fe}(\mathrm{III}), \mathrm{Cu}(\mathrm{II}), \mathrm{Ni}(\mathrm{II}), \mathrm{Co}(\mathrm{II})$ and cysteine. A curve with a number of plateaus indicates the formation of certain complex species. A plateau is obviously an indication of a $\mathrm{pH}$ range where mobility is practically constant. The first plateau in each case corresponds to a region of $\mathrm{pH}$ where metal ions are uncomplexed. In this low $\mathrm{pH}$ region, the protonated form of cysteine is maximum. Further increase in $\mathrm{pH}$ from this region onward which naturally leads to increase in ligating cysteine anion concentration $\left[\mathrm{L}^{2-}\right]$ and brings about a progressive decrease in overall ionic mobility of the metal ion species. This decrease indicates formation of complex of the metal ion with the ligand. A point is reached beyond which mobility of the metal ion species remain constant regardless of the increase of $\mathrm{pH}$ of reaction mixture. This is the second plateau which corresponds to a $\mathrm{pH}$ region in which 1:2 complex is predominantly formed. Two cysteine anion combines with each metal ion to form $\left[\mathrm{Fe}\left\{\mathrm{H}_{2} \mathrm{C}(\mathrm{S}) \mathrm{CH}\left(\mathrm{NH}_{2}\right) \mathrm{COO}\right\}_{2}\right]^{-}$, $\left[\mathrm{Cu}\left\{\mathrm{H}_{2} \mathrm{C}(\mathrm{S}) \mathrm{CH}\left(\mathrm{NH}_{2}\right) \mathrm{COO}\right\}_{2}\right]^{2-},\left[\mathrm{Ni}\left\{\mathrm{H}_{2} \mathrm{C}(\mathrm{S}) \mathrm{CH}\left(\mathrm{NH}_{2}\right) \mathrm{COO}\right\}_{2}\right]^{2-},\left[\mathrm{Co}\left\{\mathrm{H}_{2} \mathrm{C}(\mathrm{S}) \mathrm{CH}\left(\mathrm{NH}_{2}\right) \mathrm{COO}\right\}_{2}\right]^{2-}$ Complexes with $\mathrm{Fe}(\mathrm{III}), \mathrm{Cu}(\mathrm{II}), \mathrm{Ni}(\mathrm{II})$ and $\mathrm{Co}(\mathrm{II})$ respectively. Proposed molecular structures of binary complexes are given below (Figure 4). 
Where $\mathrm{M}=\mathrm{Fe}^{3+}, \mathrm{Cu}^{2+}, \mathrm{Ni}^{2+}, \mathrm{Co}^{2+}$<smiles>NC(CS[M]SCC(N)C(=O)O)C(=O)O</smiles><smiles>NC(CSP(SCC(N)C(=O)O)I(SCC(N)C(=O)O)SCC(N)C(=O)O)C(=O)O</smiles>

Figure 4. Structure of M-cysteine complexes

Beyond this plateau increase of $\mathrm{pH}$ has no effect and mobility remain constant. The overall mobility $\mathrm{U}$ is a composite parameter contributed by different ionic species of the metal ion and is given by following equation:

$$
\mathrm{U}=\frac{\mathrm{u}_{0+} \mathrm{u}_{1} K_{1}[\mathrm{~L}]+\mathrm{u}_{2} K_{1} K_{2}[\mathrm{~L}]^{2}+\ldots .}{1+K_{1}[\mathrm{~L}]+K_{1} K_{2}[\mathrm{~L}]^{2}+\ldots \ldots}
$$

Where $K^{\prime} \mathrm{s}$ are the stability constant of complexes and $[\mathrm{L}]$ is the concentration of cysteine ion. $\mathrm{u}^{\prime} \mathrm{s}\left(\mathrm{u}_{0}, \mathrm{u}_{1}, \mathrm{u}_{2}\right)$ are the ionic mobilities of different species of the metal ions which can be assessed from the plateaus of the figure. In the region between first and second plateau the system contains overwhelmingly a mixture of free metal ion and 1:1 complex. The existence of $1: 2$ complexes can be excluded and hence the third term in the numerator and the denominator of the above equation can be justifiably neglected. $\mathrm{U}$ would be equal to $\left(\mathrm{u}_{0}+\mathrm{u}_{1}\right) / 2$ provided $K_{1}[\mathrm{~L}]=1$.

Accordingly the $\mathrm{pH}$ corresponding to the average value of $\mathrm{u}_{0}$ and $\mathrm{u}_{1}$ is found from the figure and with the knowledge of the dissociation constant of cysteine $\left(\mathrm{p} k_{1}=2.00, \mathrm{p} k_{2}\right.$ $\left.=8.25, \mathrm{p} k_{3}=10.35\right)^{34}$, the concentration of cysteine ion at this $\mathrm{pH}$ is calculated. Its reciprocal gives the stability constant $K$ of the 1:1 complex. The concentration of chelating cysteine anion $\left[\mathrm{L}^{2-}\right]$ is determined as:

$$
\left[\mathrm{L}^{2-}\right]=\frac{\left[\mathrm{L}_{\mathrm{T}}\right]}{1+[\mathrm{H}] / k_{3}+[\mathrm{H}]^{2} / k_{2} k_{3}+[\mathrm{H}]^{3} / k_{1} k_{2} k_{3}}
$$

Where $\left[\mathrm{L}_{\mathrm{T}}\right]$ is the total concentration of the ligand cysteine and $k_{1}$ and $k_{2}$ are the first and second dissociation constants of the cysteine. The equillibria for dissociation of the cysteine may be given as:

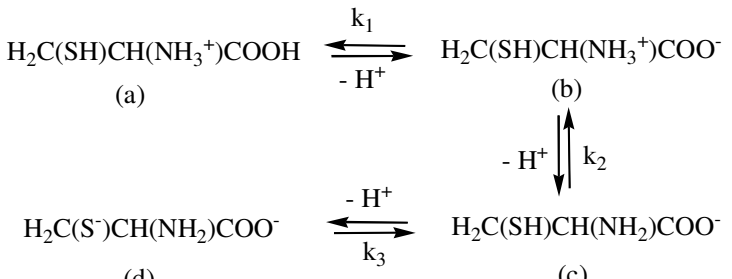

(d)

(c)

\section{Metal-cysteine-nitrilotriacetate mixed system}

Figure 3 depicts the observation of studies carried out in M-cysteine-NTA mixed complexes. These graphs clearly show the formation of two plateaus in each case. The first plateau corresponds to binary M-cysteine complexes whereas the second plateau corresponds to the formation of new complex. 
This new complex may be mixed complex of the type M-L-NTA or pure M-NTA complex. But with the help of related graphs of M-NTA complexes it was found that the absorbance difference in case of new complex is not identical to M-NTA pure complex. Further this ternary complex has greater mobility than that of binary M-cysteine complex hence these observations confirm the formation of mixed M-L-NTA complex.

Thus it is inferred that the mobility in the last plateau is due to coordination of the NTA anion to a 1:1 metal-cysteine moiety resulting in the formation of 1:1:1 mixed metalcysteine-NTA complex as.

$$
\mathrm{M}-\mathrm{L}+\mathrm{NTA} \longrightarrow K^{\prime} \longrightarrow \text { M-L-NTA }
$$

For M-L-NTA complexes the stability constant $K^{\prime}$ is calculated by using modified equation.

$$
\mathrm{U}=\frac{\mathrm{u}_{0}+\mathrm{u}_{1} K^{\prime}[\mathrm{NTA}]}{1+K^{\prime}[\mathrm{NTA}]}
$$

Here $\mathrm{u}_{0}$ and $\mathrm{u}_{1}$ are the mobilities of M-L and M-L-NTA complexes. From the Figure 3 concentration of NTA at which overall mobility is the mean of the mobilities of the two plateaus is determined by using the equation.

$$
\left[\mathrm{L}^{3-}\right]=\frac{\left[\mathrm{L}_{\mathrm{T}}\right]}{1+[\mathrm{H}] / k_{1}}
$$

The concentration of NTA anion $\left[\mathrm{L}^{3-}\right]$ at $\mathrm{pH} 8.5$ for this NTA concentration is calculated. $K$ is obviously equal to $1 /[\mathrm{NTA}]$. All these values are also reported below and clearly indicate the superior coordinating power of NTA anion to other amino acid species.

The stability constant values for binary (M-L) and ternary (M-L-NTA) complexes are $\mathrm{Fe}^{\mathrm{III}}(11.30,8.40)>\mathrm{Cu}^{\mathrm{II}}(10.00,6.80)>\mathrm{Ni}^{\mathrm{II}}(9.10,6.00)>\mathrm{Co}^{\mathrm{II}}(8.90,5.50)$ which follows the Irving William's ${ }^{35}$ order for the stability constants of transition metals of the first transition series. No comparison can be made as the literature values are not available.

\section{Conclusion}

Thus ionophoretic technique used in the above studies proved to be very useful in studying the stepwise complextion in solution. The special electrophoretic tube which has been designed for this work, yields better results after standardization. This technique provides vivid picturization of complex formation whose stability constant can be determined easily. Its further extension in the study of mixed complexation reactions is obviously a unique advancement in the realm of coordination chemistry.

\section{Acknowledgement}

Authors are thankful to the Head, Department of chemistry, University of Allahabad and UCER, Allahabad for providing research facilities.

\section{References}

1. McAuliffe C A and Murray S G, Inorg Chem Acta Rev., 1972, 6, 103.

2. Pettit L D and Bezer M, Coord Chem Rev., 1985, 61, 97-114.

3. Steiner H, Capell A, Pesold B, Citron M, Kloetzel P M, Selkel D J, Roming H, Mendla K and Haass C, J Biol Chem., 1998, 273, 32322-32331. 
4. Malthaup G, Schlickspp A, Hesse L, Beher D, Ruppert T, Master C L and Beyreuther K, Science, 1996, 271, 1406-1409.

5. Haass C and Selkol D J, Nature, 1998, 391, 339.

6. Beyreuther K and Masters C L, Nature, 1997, 389, 677.

7. Sigel H, Metal Ions in Biological Systems, vols. 1-23, Marcel Dekker, New York, 1989.

8. Sherman S E and Lippard S J, Chem Rev., 1987, 87, 1153-1181.

9. Dallinger R, Berger B, Hunjiker P and Kagi J H R, Nature, 1997, 388, 237.

10. Shimon M B, Goldshleger R and Karlish S J D, J Biol Chem., 1998, 273, 34190-34195.

11. Battersby A R, Acc Chem Res., 1993, 26, 15-21.

12. Thibaut D, Kiuchi F, Debussche L, Leeper F J and Blanche F, Chem Commun., 1992, 2, 135.

13. Hartman H A and Evenson M A, Med Hypothesis, 1992, 38(1), 75-85.

14. Bush A I, Moir R D, Williamson T G, Small D H, Rumble B, Pollwein P, Beyreuther K and Masters C L, J Biol Chem., 1993, 268, 16109-16112.

15. Beckman J S, Carson M, Smith C D and Koppenol W H, Nature, 1993, 364, 584.

16. Fell G S, Chemistry in Britain, 1980, 16(6), 323.

17. Nishino S, Kunita M, Kani Y, Ohba S, Matsushima H, Tokii T and Nishida Y, Inorg Chem Commun., 2000, 3, 145.

18. Lu Y, Roe J A, Bender C J, Peisach J, Banci L, Bertini I, Gralla E B and Valentine J S, Inorg Chem., 1996, 35, 1692-1700.

19. Pirot F, Millet J, Kalia Y N and Humbert P, Skin Pharmacol., 1996, 9, 259-269, DOI:10.1159/000211423.

20. Sidhu K S, Nash D F and McBride D E, Regul Toxicol Pharmacol., 1996, 22(1), 95-100.

21. Dourson M L, Felter S P and Robinson D, Regul Toxicol Pharmacol., 1996, 24(2), 108-120.

22. Gibson R S, Am J Clin Nutr., 1994, 59(5), 1223S-1232S.

23. Nakashima S, Kitagawa T and Olson J S, Chem Phys., 1998, 228, 323-336.

24. Kusaka Y, Kazuhiro S, Narufumi S and Yutaka H, J Occup Health, 2001, 43, 1.

25. Mamdouh S Masond and Omayma H Abd El-Hamid, Transion Met Chem., 1989, 14, 233-234.

26. Khanam J A, Begum M F, Ara J, Jesmin M, Taher A M, Ali S M M, Dhaka Univ J Pharm Sci., 2006, 5(1-2), 29-32.

27. Snell F D and Snell C T, Colorimetric Methods of Analysis, D. Van Nestrand Co. New York, 11A, 1959.

28. A. I. Vogel, A Text book of Quantitative Chemical Analysis $5^{\text {th }}$ Ed., 1989, 694.

29. Aziz S and Singh R K P, J Indian Chem Soc., 2003, 80, 680-682.

30. Praveen P Singh, Nigam V K, Pramod Kumar and Singh R K P, J Indian Chem Soc., 2009, 86, 100-103.

31. Kumar P, Singh P P, Nigam V K, Singh S and Singh R K P, Russian J Coord Chem., 2010, 36(8), 627-630.

32. Sachan S, Singh P P, Kumar P, Nigam V K and Singh R K P, Croat Chem Acta, 2011, 84(4), 461-464.

33. Shah D J, Electrophoresis Academic Press, London, 1969.

34. Martell A E and Smith R M, Critical stability constant, Amino Acid, (Plenum Press, New York and London), 1977, 1.

35. Irving H and Williams R J P, Nature, 1948, 162, 746. 